RESENDE, J.M.; COELHO, A.F.S.; CASTRO, E.C.; SAGGIN JÚNIOR, O.J.; NASCIMENTO, T.; BENEDETTI, B.C. Modificações sensoriais em cenoura minimamente processada e armazenada sob refrigeração. Horticultura Brasileira, Brasília, v.22, n.1, p. 147-150, jan-mar 2004.

\title{
Modificações sensoriais em cenoura minimamente processada e armaze- nada sob refrigeração
}

\author{
Josane Maria Resende ${ }^{1}$; Ana Flávia S. Coelho ${ }^{2}$; Elton C. de Castro² ${ }^{2}$ Orivaldo José Saggin Júnior $^{3 *}$; \\ Thiago do Nascimento ${ }^{2}$; Benedito Carlos Benedetti ${ }^{2}$ \\ ${ }^{1}$ UFLA, DCA, C. Postal 37, 37200-000 Lavras-MG; E-mail: josane.resende@agr.unicamp.br; ${ }^{2}$ UNICAMP, FEAGRI, C. Postal 6011, \\ 13083-970 Campinas-SP; ${ }^{3}$ Embrapa Agrobiologia, C. Postal 74.505, 23851-970 Seropédica-RJ *Autor para correspondência
}

\section{RESUMO}

Foram avaliadas as modificações sensoriais em cenoura minimamente processada em dois tipos de cortes durante o armazenamento sob refrigeração. Semanalmente avaliou-se a aparência, a cor, o aroma, o sabor e a textura de cenouras $\mathrm{cv}$. Nantes, minimamente processadas, acondicionadas em potes de polietileno tereftalato (PET) e armazenadas a $7^{\circ} \mathrm{C}$, por 14 dias. Para definir a freqüência de consumo e preferência pelo tipo de corte, amostras do produto foram apresentadas ao público e os resultados foram anotados em porcentagem em relação ao número total de pessoas consultadas. Com o decorrer do armazenamento houve redução nos escores para a aparência e a cor, enquanto que o sabor e a textura melhoraram em ambos os cortes. Cenouras raladas apresentaram melhor cor e aparência em relação à cenoura cortada em rodelas, entretanto o sabor e a textura foram melhores para cenouras em rodelas. As cenouras raladas são as mais indicadas para o consumo uma vez que a aparência é o atributo que mais causa impacto na escolha pelo consumidor e dentro desta a cor é a característica mais relevante. A freqüência de consumo deste tipo de produto esta aumentando gradativamente e em relação à preferência pelo tipo de corte, o consumidor optou pela cenoura ralada pela sua maior praticidade e versatilidade de uso.

Palavras-chave: Daucus carota, minimamente processado, qualidade, fatiamento, conservação.

\section{ABSTRACT}

Sensory modifications of fresh cut carrots stored under refrigeration

Sensory modifications were evaluated in carrots cv Nantes lightly processed in two kinds of cut (grated and sliced) during the storage under refrigeration. Fresh cut carrots were packed in polyethylene tereftalato (PET) boxes and stored at $7^{\circ} \mathrm{C}$ for 14 days. The carrot's appearance, color, aroma, flavor and texture were evaluated weekly. To obtain the frequency of consumption and preference of kind of cut, samples were offered to people to try. During the storage of both kinds of cut, a reduction in scores for appearance and color occurred, while flavor and texture scores were improved. Fresh cut carrots in the grated form presented better color and appearance than the fresh cut in the sliced form. However, flavor and texture were better in carrots cut in the sliced form. The grated carrots are the most indicated for consumption because appearance is the attribute that causes most impact to consumers, besides the color. The frequency of consumption of fresh cut carrots is increasing gradually and, regarding people's preference for kind of cut, the consumers opted for grated carrot because of the larger practicability and versatility in use.

Keywords: Daucus carota, quality, slicing, storage-life.

\section{(Recebido para publicação em 30 de outubro de 2002 e aceito em 10 de outubro de 2003)}

$\mathrm{D}$ as hortaliças minimamente proces sadas, a cenoura é uma das mais populares, pela sua versatilidade de uso e formas de apresentação ao consumidor, podendo ser ralada em diversos tamanhos ou cortada na forma de fatias, cubos, palitos, e ainda apresentada na forma de mini-cenoura "baby-carrot" (Lana, 2000). Em função do processamento tornam-se suscetíveis a várias mudanças fisiológicas e microbiológicas que depreciam a sua qualidade sensorial e limitam sua vidade-prateleira.

Vários autores têm investigado a influencia do tipo de processamento e das condições de armazenamento sobre a percepção da qualidade em produtos minimamente processados (SolivaFortuny e Martín-Belloso, 2003; Jacxsens et al., 2003; Freire Júnior et al., 2002; Gorny et al., 2000). A vidade-prateleira destes produtos muitas vezes é inadequada induzindo à perda da firmeza e da cor, sintetizando compostos fenólicos responsáveis pelo sabor amargo, ácido e adstringente (Fortuny e Martín-Belloso, 2003; Talcott et al., 2001; Talcott e Howard, 1999; Li e Barth, 1998)

Não só o metabolismo próprio do tecido vegetal, mas também os microrganismos, são responsáveis pela presença de odores e sabores desagradáveis durante o armazenamento de hortaliças minimamente processadas. Kakiomenou et al. (1996) isolaram Leuconostoc mesenteroides, como principal bactéria láctica contaminante de cenoura ralada. A contaminação é caracterizada pela presença de sabor e aroma ácido devido à produção de metabólitos como ácido láctico e ou acético acompanhado da produção de "limo" e perda de textura (Jacxsens et al., 1999; Carlin et al., 1989). A alta contaminação com este tipo de bactéria está associada à sanitização ruim das máquinas de corte, abuso de temperatura ou ainda ao período de armazenamento muito longo (Dijk et al., 1999).

Jacxsens et al. (2003) estudaram a relação entre qualidade microbiologica, produção de metabólitos e qualidade sensorial de alguns produtos minimamente processados. Constataram uma relação entre o crescimento de microrganismos contaminantes, as propriedades sensoriais e a produção de metabólitos onde bactérias lácticas e leveduras formam a microflora contaminante dominante. As propriedades sensoriais foram o fator limitante no 
Tabela 1. Escores médios para a aparência, cor, aroma, sabor e textura de cenouras minimamente processadas, armazenadas em diferentes tempos, a $7^{\circ} \mathrm{C}$. Campinas, UNICAMP, 2001.

\begin{tabular}{lccc}
\hline \multirow{2}{*}{ Atributos } & \multirow{2}{*}{$\begin{array}{c}\text { Armazenamento } \\
\text { (dias) }\end{array}$} & \multicolumn{2}{c}{ Cortes } \\
\cline { 3 - 4 } Aparência & 0 & Rodelas & Ralada \\
& 7 & $6,9 \mathrm{Aa}$ & $6,4 \mathrm{Aa}$ \\
& 14 & $4,8 \mathrm{Ab}$ & $4,7 \mathrm{Ab}$ \\
Cor & 0 & $4,2 \mathrm{Ab}$ & $5,2 \mathrm{Aab}$ \\
\hline \multirow{3}{*}{ Aroma } & 7 & $6,2 \mathrm{Aa}$ & $5,6 \mathrm{Aa}$ \\
& 14 & $4,2 \mathrm{Ab}$ & $3,6 \mathrm{Ab}$ \\
& 0 & $3,7 \mathrm{Ab}$ & $4,0 \mathrm{Ab}$ \\
\hline \multirow{3}{*}{ Sabor } & 7 & $7,2 \mathrm{Aa}$ & $6,6 \mathrm{Aa}$ \\
& 14 & $6,5 \mathrm{Aa}$ & $6,1 \mathrm{Aa}$ \\
& 0 & $6,7 \mathrm{Aa}$ & $6,5 \mathrm{Aa}$ \\
\hline \multirow{3}{*}{ Textura } & 7 & $5,0 \mathrm{Aab}$ & $4,1 \mathrm{Aa}$ \\
& 14 & $4,1 \mathrm{Ab}$ & $3,7 \mathrm{Aa}$ \\
& 0 & $6,1 \mathrm{Aa}$ & $4,6 \mathrm{Ba}$ \\
\hline
\end{tabular}

Médias com a mesma letra maiúscula na linha, dentro do mesmo período de armazenamento $\mathrm{e}$ minúscula na coluna dentro do mesmo corte não diferem entre si pelo teste de Duncan a 5\%.

consumo destes produtos, em geral minimamente processados; foram rejeitados com base na cor, antes mesmo do sabor, do aroma e da contaminação microbiana tornar-se um problema. Estes autores salientam ainda que a vidade-prateleira de hortaliças minimamente processadas não deve ser avaliada somente sobre a contagem bacteriana mas também sobre atributos de qualidade sensorial.

A análise sensorial é uma forma adicional, rápida e criteriosa para avaliar a vida-de-prateleira de produtos minimamente processados, pois baseia-se principalmente no paladar, olfato e tato para avaliação de atributos físicos e químicos (Matthheis e Fellman, 1999; Meilgaard et al., 1991; Moraes, 1988; Chaves, 1980).

Avaliou-se alterações nos principais atributos sensoriais de cenoura minimamente processada em dois tipos de cortes durante o armazenamento.

\section{MATERIAL E MÉTODOS}

Raízes de cenouras da cultivar Nantes foram adquiridas no comércio varejista de Campinas (SP), levadas ao laborató- rio de pós-colheita da UNICAMP e selecionadas quanto à ausência de defeitos e uniformidade no tamanho das raízes. Após, foram lavadas em água corrente e colocadas para drenar o excesso de água em bancada sanitizada.

Quinze kg de cenoura foram descascadas manualmente retirando o topo e a ponta das raízes com faca afiada e separadas em dois lotes para a realização dos cortes. No primeiro lote as cenouras foram raladas e no segundo, fatiadas em rodelas; ambos os cortes xílio de um multiprocessador Arno, mudando-se apenas o disco de corte.

Os cortes foram sanificados separadamente em água contendo 100 ppm de cloro por 5 minutos, drenados, colocados em sacos de náilon e centrifugados por $5 \mathrm{~min}$. Os cortes em rodelas e ralados foram embalados, separadamente, em potes de polietileno tereftalato (PET) com tampas e armazenados a $7^{\circ} \mathrm{C} \pm 3^{\circ} \mathrm{C}$, por 14 dias.

Utilizou-se o delineamento inteiramente casualisado em esquema fatorial $2 \times 3$ (dois níveis do fator corte: ralado e em rodelas; e três níveis do fator tempo: 0; 7 e 14 dias de armazenamento), com três repetições, sendo a unidade foram feitos mecanicamente, com au- experimental composta de um pote de polietileno tereftalato (PET) contendo $200 \mathrm{~g}$ de cenoura minimamente processada. Semanalmente foram retiradas amostras para análise sensorial da aparência geral, cor característica de cenoura fresca (recém cortada), aroma característico, sabor (doçura) e textura (crocância).

Para obter a freqüência de consumo e a preferência pelo tipo de corte, amostras do produto processado nas mesmas condições foram acondicionadas no mesmo tipo de embalagem e apresentadas no mesmo dia ao público, em diferentes pontos do campus da UNICAMP, simulando o ponto de venda. Os resultados foram anotados como porcentagem em relação ao número total de pessoas consultadas.

A análise sensorial foi feita por uma equipe de 21 provadores não treinados, onde cada um recebeu durante três semanas seis amostras codificadas, que correspondiam aos dois tipos de cortes, em três repetições. As amostras foram retiradas da câmara fria e deixadas sobre a bancada até atingirem a temperatura ambiente e, em seguida foram acondicionadas em recipientes adequados para prova e servidas aos provadores em cabines individuais. Os resultados das análises individuais de aparência, cor, aroma, sabor e textura foram registrados em escala não estruturada de $9 \mathrm{~cm}$ em que o lado esquerdo corresponde à menor intensidade (valor 0) e o lado direito à maior intensidade (valor 9). As variáveis avaliadas foram submetidas à análise de variância e as médias comparadas pelo teste de Duncan em nível de 5\%.

\section{RESULTADOS E DISCUSSÃO}

\section{Análise sensorial}

Não houve interação significativa entre os tipos de corte e o tempo de armazenamento nas condições do experimento. $\mathrm{O}$ efeito isolado de cada fator sobre algumas variáveis que caracterizam a qualidade sensorial e a vida-deprateleira de cenouras minimamente processadas será discutido a seguir.

$\mathrm{O}$ armazenamento e os tipos de corte afetaram a qualidade das cenouras quando se estabeleceu uma escala de escores de 0 a 9, onde 0-3 é ruim; 4-6 é 
boa e 7-9 é excelente. As cenouras processadas na forma de rodelas apresentaram melhor textura, sabor e aroma e, a ralada teve melhor aparência e cor aos 14 dias de armazenamento.

$\mathrm{O}$ armazenamento influenciou significativamente a aparência e a cor das cenouras (Tabela 1). Ambos os cortes apresentaram redução nos escores para aparência e cor com o decorrer do armazenamento. Embora não tenham sido detectadas diferenças significativas entre os cortes, a aparência e a cor foram superiores para cenoura ralada ao final do armazenamento. Este resultado era esperado, uma vez que a cor está diretamente relacionada à aparência. As cenouras raladas, conservaram melhor a aparência e a cor em função dos pedaços menores ficarem mais agregados mantendo a umidade mais elevada no interior da embalagem além da maior capacidade de retenção da superfície de corte lisa, homogênea e hidratada em comparação à superfície áspera, quebradiça e desidratada da cenoura em rodelas (observação pessoal).

A perda da aparência satisfatória em cenouras minimamente processadas é geralmente atribuída a fatores que contribuem para o desenvolvimento de uma superfície "esbranquiçada". Este fenômeno provavelmente é atribuído à desidratação externa da superfície do corte, e poderá ser acompanhado por síntese de lignina. Ambos podem estar diretamente relacionados com a extensão da superfície exposta ao dano (Barry-Ryan e O’Beirne, 1998).

A aparência é o atributo que mais causa impacto na escolha por parte do consumidor e dentro desta, a cor é a característica mais relevante. Isto porque a cor caracteriza sobremaneira o produto, constituindo-se no primeiro critério para sua aceitação ou rejeição. A aparência geral e a cor estão relacionadas com a qualidade, índice de maturação e deterioração do produto. $\mathrm{O}$ consumidor espera uma determinada cor para cada alimento e qualquer alteração nesta, pode diminuir sua aceitabilidade (Modesta, 1994; Deliza, 2000).

Para o aroma não houve diferença significativa entre tipos de corte no decorrer do armazenamento (Tabela 1). Os resultados mostraram que o aroma se manteve constante durante o armazenamento, variando de 7,2 a 6,7 para cenoura em rodelas e de 6,6 a 6,5 para cenoura ralada aos 0 e 14 dias de armazenamento respectivamente. $\mathrm{O}$ resultado já era esperado, uma vez que a maioria dos compostos voláteis das cenouras são perdidos durante as operações de pré-processamento e processamento (Howard et al., 1996).

Para sabor e textura houve diferenças significativas, tanto para o tempo de armazenamento quanto para o tipo de corte (Tabela 1). Houve diferença significativa para o sabor entre o $7^{\circ}$ e $14^{\circ}$ dia de armazenamento para o corte em rodelas. No $14^{\circ}$ dia o escore atribuído $(6,1)$ foi maior em relação ao $7^{\circ}$ dia $(4,1)$. Para cenoura ralada não houve diferença significativa. A textura teve comportamento semelhante para ambos os cortes. Houve diferença significativa entre os 7 e 14 dias de armazenamento quando os escores atribuídos foram respectivamente de 6,1 e 7,5 para cenoura em rodela e 4,6 e 6,3 para cenoura ralada (Tabela 1 ). O tempo de armazenamento teve efeito positivo sobre o sabor e a textura.

Os tipos de cortes influenciaram significativamente o sabor e a textura da cenoura. $\mathrm{O}$ corte em rodelas mostrouse superior para ambos os atributos sensoriais. Em cenouras processadas na forma de rodelas os tecidos internos sofreram menor ruptura das células e produção de exudatos, que contribuíram para uma menor degradação dos compostos não voláteis responsáveis pelo manutenção do sabor. Em cenouras processadas o sabor tem sido caracterizado pelo uso das sensações básicas do gosto (doce, ácido ou amargo), efetivas para descrever os principais constituintes não voláteis, pois os valáteis são reduzidos durante as operações de préprocessamento (Talcott et al., 2001).

A maior textura dos cortes em rodelas se deve provavelmente à perda de umidade durante o armazenamento, promovendo maior crocância. A perda de matéria fresca da cenoura minimamente processada é o somatório da perda de carbono por meio da respiração que ocorre durante todo o tempo de armazenamento (Izumi et al., 1996).

$\mathrm{O}$ armazenamento e o tipo de corte afetaram a qualidade sensorial e vida- de-prateleira da cenoura. A aparência e a cor foram afetadas negativamente, enquanto que o sabor e a textura melhoraram com o decorrer do armazenamento para ambos os tipos de cortes. A aparência e a cor foram consideradas melhores para cenouras raladas e o sabor e a textura foram melhores para cenouras processadas em rodelas. A aparência é o principal atributo para aquisição de um produto, e dentro desta a cor. Assim conclui-se que para as cenouras minimamente processadas a forma ralada é a mais indicada para o consumo.

Freqüência de consumo e teste de preferência

Constatou-se que $59 \%$ dos entrevistados consome freqüentemente o produto, menos de $40 \%$ o consome ocasionalmente e uma porcentagem muito baixa não o consome. Embora seja relativamente recente a introdução de produtos minimamente processados no mercado brasileiro, o seu consumo tem aumentado rapidamente. A redução nos núcleos familiares e o crescente ingresso da mulher no mercado de trabalho, com conseqüente redução de tempo disponível para o preparo de frutas e hortaliças de forma tradicional, têm levado os consumidores a demandarem cada vez mais produtos que recebem algum tipo de preparo. Na escolha de hortaliças pré-processadas os consumidores optam por fatores como praticidade, facilidade de preparo, higiene, aparência, sabor e qualidade nutricional. Com seu elevado valor nutricional a cenoura participa como fonte importante de $\beta$ caroteno (pró-vitamina A), minerais e possui baixa caloria.

Sempre que possível, produtos processados, devem ser submetidos ao teste de preferência para se conhecer a reação do consumidor e observar se a forma, a embalagem ou aparência são adequados.

No presente ensaio as cenouras minimamente processadas por dois tipos de cortes foram apresentadas ao público para determinar o corte de maior preferência. Possivelmente, pela versatilidade e praticidade no uso, $64 \%$ das pessoas preferiram a cenoura ralada. A praticidade é o predicado que a maioria dos consumidores leva em consideração na hora da escolha dos pré-processados. 


\section{AGRADECIMENTOS}

À FAPESP e PRODETAB/ Embrapa, pelo auxílio financeiro.

\section{LITERATURA CITADA}

BARRY-RYAN, C.; O'BEIRNE, D. Quality and shelf-life of fresh cut carrot slices as affected by slicing method. Journal of Food Science, v.63, n.5, p.851-856, 1998.

CARLIN, F.; NGUYEN-THE, C.; CUDENNEC, P.; REICH, M. Microbiological spoilage of fresh ready-to-use carrots. Science Aliments, v.9, p.371386, 1989.

CHAVES, J.B.P. Avaliação sensorial de alimentos (Métodos de Análises). Viçosa: UFV, 1980. 69 p.

DELIZA, R. Importância da qualidade sensorial em produtos minimamente processados. In: ENCONTRO NACIONAL SOBRE PROCESSAMENTO MÍNIMO DE FRUTAS E HORTALIÇAS, 2. 2000, Viçosa, MG. Palestras... Viçosa: UFV, 2000. p.73-74.

DIJK, R.; BEUMER, R.; DE BOER, E.; BOSBOOM, M.; BRINKMAN, E.; DEBEVERE J.; VAN DIJK, J.; DIJKSTRA A.; STEGEMAN, H. Microbiologie van voedingsmiddelen: methoden, principes en criteria. The Netherlands: Keesing Noordervliet, Houten, 1999. 464 p. FREIRE JÚNIOR, M.; DELIZA, R.; CHITARRA, A.B. Alterações sensoriais em alface hidropônica cv. Regina minimamente processada e armazenada sob refrigeração. Horticultura Brasileira, Brasília, v.20, n.1, p.63-66, 2002.
GORNY, J.R.; CIFUENTES, R.A.; HESSPIERCE, B.H.; KADER, A.A. Quality changes in fresh-cut pear slices as affected by cultivar, ripeness stage, fruit size and storage regime. Journal of Food Science, v.65, p.541-544, 2000. HOWARD, L.R.; BRASWELL, D.D.; ASELAGE, J. Chemical composition and color of strained carrots as afected by processing. Journal of Food Science, v.61, p.327-330,1996. IZUMI, H.; WATADA, A.E.; KO, N.P.; DOUGLAS, W. Controlled atmosphere storage of carrots slices, sticks and shreds. Postharvest Biology and Technology, v.9, n.2, p.165-172, 1996. JACXSENS, L.; DEVLIEGHERE, F.; FALCATO, P.; DEBEVERE, J. Behaviour of $L$. monocytogenes and Aeromonas spp. on fresh-cut produce packaged under equilibrium modified atmosphere. Journal Food Protection, v.62, p.1128-1135, 1999.

JACXSENS, L.; DEVLIEGHERE， F.; RAGAERT, P.; VANNESTE, E.; DEBEVERE, J. Relation between microbiological quality, metabolite production and sensory quality of equilibrium modified atmosphere packaged freshcut produce. International Journal of Food Microbiology, v.83, p.263-280, 2003.

KAKIOMENOU, K.; TASSOU, C.; NYCHAS, G. Microbiological, physiochemical and organoleptic changes of shredded carrots stored under modified storage. International Journal of Food Science Technology, v.31, p.359-366, 1996. LANA, M.M. Aspectos da fisiologia de cenoura minimamente processada. Horticultura Brasileira, Brasília, v.18, n.3, p.154-158, 2000.
LI, P.; BARTH, M.M. Impact of edible on nutritional and physiological changes in lightlyprocessed carrots. Postharvest Biology and Technology, v.14, p.51-60, 1998

MATTHHEIS, J.P.; FELLMAN, J. K. Preharvest factors influencing flavor of fresh fruit and vegetables. Postharvest Biology and Technology, v.15, p.227-232, 1999.

MEILGAARD, M.; CIVILLE, G.V.; CARR, B.T. Sensory evaluation techniques. 2. ed. Boca Raton, FL: The CRC Press, 1991. p.174-175

MODESTA, R.C.D. Manual de análise sensorial de alimentos e bebidas. Rio de Janeiro EMBRAPA-CTAA, 1994. $67 \mathrm{p}$.

MORAES, M.A Método para avaliação sensorial dos alimentos, 6 ed. Campinas: Editora da UNICAMP, 1988. 93 p. (Série Manuais).

SOLIVA-FORTUNY, R.C.; MARTÍNBELLOSO, O. New advances in extending the shef-life of fresh-cut fruits: a review. Trends in Food Science \& Technology, v.14, p.341-353, 2003.

TALCOTT, S.T.; HOWARD, L.R. Chemical and sensory quality of strained carrots as infuenced by stress induced phenolic compounds. Journal of Agricultural and Food Chemistry, v.47, p.13621366, 1999;

TALCOTT, S.T.; HOWARD, L.R.; BRENES, C.H. Factors contributing to taste and quality of commercially processed strained carrots. Food Research International, v.34, p.31-38, 2001. 